\title{
IMRT using simultaneously integrated boost (SIB) in head and neck cancer patients
}

\author{
G Studer*1, PU Huguenin ${ }^{1}$, JB Davis², G Kunz², UM Lütolf ${ }^{1}$ and \\ C Glanzmann ${ }^{1}$
}

\author{
Address: ${ }^{1}$ Department of Radiation Oncology, University Hospital, Zurich, Switzerland and ${ }^{2}$ Department of Radiation Physics, University \\ Hospital, Zurich, Switzerland \\ Email: G Studer* - gabriela.studer@usz.ch; PU Huguenin - pia.huguenin@usz.ch; JB Davis - bernard.davis@usz.ch; \\ G Kunz - guntram.kunz@usz.ch; UM Lütolf - urs.l@usz.ch; C Glanzmann - christoph.glanzmann@usz.ch \\ * Corresponding author
}

Published: 3I March 2006

Radiation Oncology2006, 1:7 doi:10.1186/1748-717X-1-7

This article is available from: http://www.ro-journal.com/content/l/I/7

(c) 2006Studer et al; licensee BioMed Central Ltd.

This is an Open Access article distributed under the terms of the Creative Commons Attribution License (http://creativecommons.org/licenses/by/2.0), which permits unrestricted use, distribution, and reproduction in any medium, provided the original work is properly cited.
Received: 22 November 2005

Accepted: 31 March 2006

\begin{abstract}
Background: Preliminary very encouraging clinical results of intensity modulated radiation therapy (IMRT) in Head Neck Cancer (HNC) are available from several large centers. Tumor control rates seem to be kept at least at the level of conventional three-dimensional radiation therapy; the benefit of normal tissue preservation with IMRT is proven for salivary function. There is still only limited experience with IMRT using simultaneously integrated boost (SIB-IMRT) in the head and neck region in terms of normal tissue response.
\end{abstract}

The aim of this work was (I) to establish tumor response in HNC patients treated with SIB-IMRT, and (2) to assess tissue tolerance following different SIB-IMRT schedules.

Results: Between I/2002 and I2/2004, I 5 HNC patients have been curatively treated with IMRT. $70 \%$ received definitive IMRT (dIMRT), 30\% were postoperatively irradiated. In $78 \%$ concomitant chemotherapy was given.

SIB radiation schedules with 5-6 × 2 Gy/week to 60-70 Gy, $5 \times 2.2$ Gy/week to 66-68.2 Gy (according to the RTOG protocol H-0022), or $5 \times 2$.II Gy/week to $69.6 \mathrm{~Gy}$ were used.

After mean 18 months (10-44), 77\% of patients were alive with no disease. Actuarial 2-year local, nodal, and distant disease free survival was $77 \%, 87 \%$, and $78 \%$, respectively. $10 \%$ were alive with disease, $10 \%$ died of disease. 20/2I locoregional failures occurred inside the high dose area. Mean tumor volume was significantly larger in locally failed $(63 \mathrm{cc})$ vs controlled tumors $(32 \mathrm{cc}, \mathrm{p}<0.0 \mathrm{I})$, and in definitive $(43 \mathrm{cc})$ vs postoperative IMRT $(25 \mathrm{cc}, \mathrm{p}<0.05)$; the locoregional failure rate was twofold higher in definitively irradiated patients.

Acute reactions were mild to moderate and limited to the boost area, the persisting grade 3/4 late toxicity rate was low with $6 \%$. The two grade 4 reactions (dysphagia, laryngeal fibrosis) were observed following the SIB schedule with 2.2 Gy per session.

Conclusion: SIB-IMRT in HNC using 2.0, 2.1 I or $2.2 \mathrm{~Gy}$ per session is highly effective and safe with respect to tumor response and tolerance. SIB with $2.2 \mathrm{~Gy}$ is not recommended for large tumors involving laryngeal structures. 


\section{Background}

Preliminary very encouraging clinical results of IMRT in HNC are available from several large centers [1-6]. Tumor control rates seem to be kept at least at the level of conventional three-dimensional radiation therapy (3DCRT); the benefit of normal tissue preservation with IMRT is proven for salivary function; reduced dose exposure of the mandibular bone is described (manuscript submitted).

There is still only limited experience with simultaneously integrated boost (SIB) application in the head and neck region in terms of normal tissue response. As known from 3DCRT, dose, fractionation and treated volumes are the tumor control and normal tissue tolerance defining parameters. Dosimetric and volumetric relationships need to be newly defined for SIB, as the radiobiological response of intermediate dose volumes encompassing relatively small high-dose areas with increased doses per fraction seems to substantially differ from the situation in conventional techniques.

The intention of this prospective study was to present 3year experiences in SIB-IMRT of HNC patients, focused on tumor response and tissue tolerance following different SIB schedules.

\section{Results}

115 of 310 head and neck carcinoma (HNC) patients referred to our radiation oncology institution were treated curatively with IMRT (nasopharyngeal tumors excluded from analysis). The analysed patients were irradiated between January 2002 and December 2004; the mean follow up time was 18 months $(10-44)$.

The median age was 60 years $(15-85)$, with a male to female ratio of $3.4: 1$ ( 89 men, 26 women). The WHO Performance Status was 0 in 87,1 in 26 , and 2 in two patients. 71 patients $(62 \%)$ of the entire cohort presented with a T3/4 or T1-2/N2c, N3 tumor, 13 individuals (11\%) were referred for radiation of a recurrent tumor. Tumor subsites are listed in Table 1 . The TN distribution consisted of $9 \% \mathrm{~T} 1,28 \% \mathrm{~T} 2,52 \% \mathrm{~T} 3 / 4$ stages, and $11 \%$ recurrent situations, respectively. $23 \%$ of all patients presented with a N2c/3 nodal stage.

The specific aims for performing IMRT were parotid gland sparing ( $\mathrm{n}$ 100), and/or mandible bone sparing $(\mathrm{n}=76)$ and/or anterior visual pathway and/or brain sparing ( $\mathrm{n}=$ $10)$.

34 patients (30\%, 30 following an $\mathrm{R} 1$ resection) were treated in a postoperative setting, 80 patients (70\%) underwent a primarily definitive radiation, re-irradiation after high dose 3DCRT was performed in one patient. One patient received preoperative irradiation.

Concomitant cisplatin based weekly chemotherapy (40 $\mathrm{mg} / \mathrm{m}^{2}$, once a week, 1-7 cycles) was given to 89 patients (77\%). 61/89 patients (69\%) received $5-7$ cycles (depending on the fractionation regime); 18 (20\%) underwent 4 cycles, 10 (11\%) only tolerated between 1 3 cycles. No treatment interruption was related to actinic toxicity; total treatment time was mean 46 days $(33-60)$.

\section{Tumor response and survival}

Actuarial 2-year local, nodal and distant disease free survival was 77,87 and $78 \%$, respectively (Figures 1- 5). At the time of data analysis (November 2005), 88/115 patients were alive with no evidence of disease (ANED, 77 $\%), 11$ patients were alive with local and/or distant disease (AD, $10 \%) .12 / 14$ patients died of disease (DOD, 10 $\%)$, two died with intercurrent disease.

21/115 patients (18\%) experienced loco-regional failure (recurrence in 13, tumor persistence in 8, Table 2). 12/13 recurrences developed inside PTV1 ('in field', covered by $>95 \%$ PTD), in one case marginal recurrence occurred in the distal, cervical aspect of the initial tumor arising from the floor of the mouth. No failure occurred related to/in the adjacent tissue of spared parotid gland.

In loco-regionally failed cases, doses $<95 \%$ were delivered to mean $13.5 \%(0-50)$ of PTV1, vs mean $8 \%(0-$ 24 ) in loco-regionally controlled individuals $(\mathrm{p}>0.5$,

Table I: Diagnoses and related primary tumor $(T)$ stage distribution in I I 5 IMRT patients.

\begin{tabular}{|c|c|c|c|c|c|c|}
\hline & Recurrence & TI & $\mathrm{T} 2$ & T3 & $\mathrm{T} 4$ & Total \\
\hline Oropharynx & 3 & 7 & 16 & 16 & 14 & 56 \\
\hline Oral cavity & 5 & 2 & 5 & 2 & 5 & 19 \\
\hline Hypopharynx & 0 & 1 & 6 & 4 & 5 & 16 \\
\hline PNS & 2 & 0 & 0 & 0 & 10 & 12 \\
\hline Supraglottic & 0 & 0 & 5 & 1 & I & 7 \\
\hline Others & 3 & 0 & 0 & 1 & 0 & 5 \\
\hline Total & 13 & 10 & 32 & 24 & 36 & 115 \\
\hline
\end{tabular}

PNS: paranasal sinus tumors others: thyroid (2), glottic (I), orbital (I) and parotid gland (I) tumors 


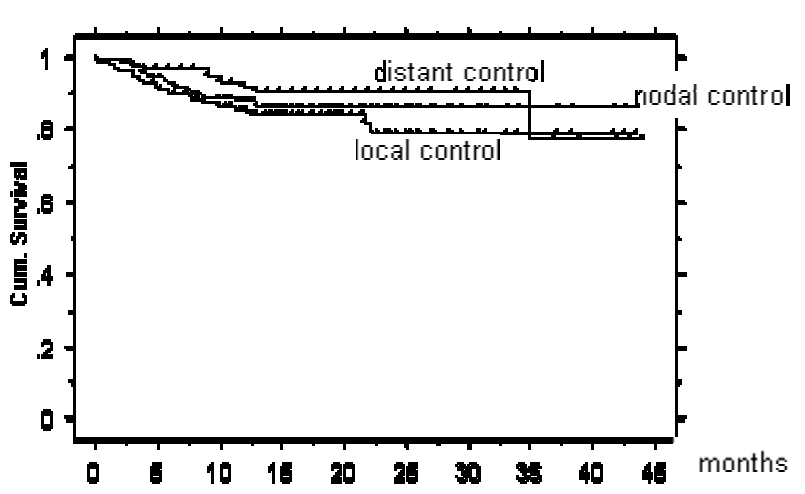

Figure I

Actuarial 2 year local, nodal, and distant disease free survival: $77 \%, 87 \%$, and $78 \%$, respectively

Table 3). 5 loco-regionally controlled patients suffered from distant failure.

Local failure occurred twice as often in definitively as in postoperatively irradiated patients, with 15/80 (19\%) vs $3 / 34$ (9\%) (Figure 5), respectively; nodal failure rate was $11 / 80(14 \%)$, vs $1 / 34$ (3\%) distant failure rate $6 / 80$ (8 $\%)$ vs $4 / 34$ (12\%), respectively. Tumor volumes in the definitive vs postoperative IMRT subgroup differed significantly with mean/median $43 / 32$ cc $(3-205)$ vs $24.7 / 14$ cc $(2-74)$, respectively $(\mathrm{p}<0.05)$.

The primary GTV measured mean $38.2 \mathrm{cc}(2-206)$, the nodal GTV mean $12 \mathrm{cc}(1-70)$. The mean volume of the primary GTV in patients who failed locally was 63 cc (13 - 206) and differed significantly from mean 32 cc (range $2-124)$ in locally controlled patients ( $p<0.01$, Table 3$)$.

\section{Early toxicity}

Xerostomia grade 3 was observed in $10 \%$ of patients at completion of treatment. Mucositis (15\% grade 3 ), and dermatitis ( $5 \%$ grade 3 ) were limited to the high dose volume. Grade 3 dysphagia developed in only $20 \%$ of the cases, translating into an improved patient's performance status during treatment (QoL analysis in preparation). No grade 4 early reaction, and no radiation-toxicity related treatment interruption occurred.

A gastric feeding tube was used in 37 patients (33\%), in the majority of them prior to IMRT start because of pretreatment weight loss due to pain or tumor-related mechanic dysphagia. The mean weight loss at completion of IMRT was $6 \%$ (range: $25 \%$ loss to $15 \%$ gain under treatment); $19 / 113$ patients (17\%) lost $\geq 10 \%$ of their initial weight; one third of them despite feeding tube (>10 $\%$ loss in $20 \%$ of patients of whom feeding tube was

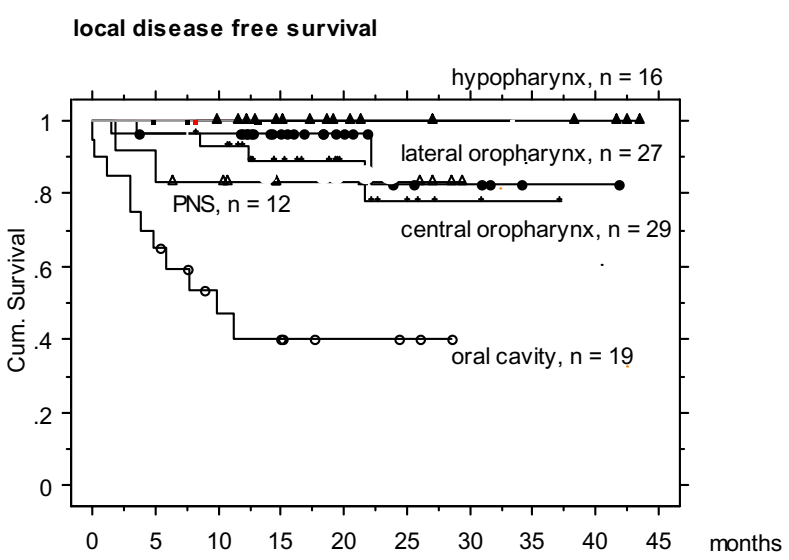

Figure 2

Actuarial 2 year local disease free survival in different HNC entities. Hypopharyngeal tumors revealed the highest local control rates, while oral cavity tumors showed the lowest rate. This fact can not be explained by TN stages or tumor volumes, and is issue of further data anaylses.

inserted in $33 \%$ ). $42 \%$ of all patients kept pre-treatment weight $(n=45)$ or gained weight under treatment $(n=8)$.

\section{Subacute and late toxicity (> 90 days from treatment completion)}

$19(18 \%)$ grade $3 / 4$ subacute or late effects (included 2 cases with a grade 3 xerostomia) in 18 out of 109 individuals treated with SIB-IMRT, were observed so far (Table 4); all lesions were localized in the high dose SIB area (PTV1, mean $176 \mathrm{cc}$, range 78 - 299), and developed 2 - 12 months after SIB-IMRT completion. This includes a dysphagia grade 4, a laryngeal fibrosis grade 4 requiring a permanent tracheostoma, an osteo-radionecrosis grade 3 of the mandible, which was resolved by lingual bone decortication, grade 3 dysphagia in 2 cases, grade 3 xerostomia 1 year after IMRT in 2 (in one of them no parotid gland sparing was performed), and mucosal ulcers in 12 cases.

The most frequent grade 3/4 late term effect was mucosal ulceration in the area of the SIB. This was characterized by its appearance mean 4 months $(2-6)$ after IMRT completion, by its persistence for mean 3 months $(1-7)$, and spontaneous healing in all locally controlled cases. All ulcers occurred in oro-hypopharyngeal and oral cavity tumor patients, no ulcer was observed in paranasal sinus or nasopharyngeal cancer patients. In 3 patients who suffered from persisting ulceration for a period longer than 7 months, underlying tumor persistence was histologically confirmed 8, 10 and 11 months after completion of treatment. One of these three patients experienced substantial ulcer bleeding from the large tumor ulceration which was already present before IMRT start. 
local disease free survival



Figure 3

Actuarial 2 year local disease free survival according to the T-stages.

In grade $3 / 4$ event patients (Table 4 ), mean $1.3 \%$ ( 0 -10 $\%$, or $0-7.7 \mathrm{cc}$ ) of the entire PTV1 received more than $110 \%$ of the prescribed total dose. In 9 of the 19 cases, maximal doses were below $110 \%$; in only 4/19 patients, a hot spot area was matching with the area of a grade $3 / 4$ tissue lesion.

The patient with grade 4 laryngeal fibrosis became symptomatic after a latency of 12 months following treatment with SIB 2.2 to 66 Gy for a large T4 hypopharyngeal cancer that involved the oropharynx, hypopharynx and larynx. No hot spot was delivered to the area of the actinic lesion. 3.5 years post treatment, this patient is free of disease.

The 3 patients with grade 3/4 dysphagia were treated for extended T3 primaries of the hypopharynx (2) and oropharynx (1); all three affected patients are women. After follow up periods of 9 and 14 months, no improvement was observed in two; a third patient was lost of follow up 9 months after treatment completion.
SIB-IMRT resulted in a 1-year swallowing / salivary function of grade 0 -1 dysphagia / xerostomia in 95 / $80 \%$ (n $=77$ ). In only 2 patients, less than $30 \%$ of the total parotid gland volume (both parotid glands $=100 \%$ volume) could be kept below mean doses of $26 \mathrm{~Gy}$; in $74 \%$ of the patients the spared glandular total volume ranged between $60 \%$ and $100 \%$, in 25\% of the patients, the protected glandular volume ranged between 30 and $60 \%$ (Figure 7 and Figure 8 illustrate an example of spared total parotid gland volume of $62 \%$ ).

When late reactions are analysed according to the different SIB schedules, the following distribution was found: 7 events developed in the $33 \mathrm{SIB}^{2.2}$ cases (21\%), 10 events in the $47 \operatorname{SIB} 2.11(21 \%)$, and 2 in the 22 of 29 SIB 2.0 patients $(9 \%)$ with doses > $65 \mathrm{~Gy}$.

In locally controlled patients, 6 persistent late effects were observed: xerostomia (2), laryngeal fibrosis (1), and dysphagia (3), last assessed at 14 months, 3.5 years, and 9 17 months after completion of IMRT, respectively. This translates into a grade $3 / 4$ toxicity rate of $\sim 6 \%(5 / 80)$ in the $\operatorname{SIB}^{2.11 / 2.2}$ subgroup, or of $5.5 \%(6 / 109)$ in the entire SIB-IMRT cohort, respectively.

At one year post treatment, mean weight loss was $4 \%$ (range minus $24 \%$ to plus $13 \%$ of pre-treatment value); $7 / 77$ patients with 1 year follow up still had $\geq 10 \%$ less weight than before treatment, 18 patients reached their initial weight or more $(n=10)$.

\section{Discussion}

\section{Disease control}

The high 2-year locoregional disease free survival as well as the locoregional failuare pattern in our patients is comparable to the excellent results reported in the literature on IMRT of head and neck tumors (Table 5). Most of these results are superior to historic results following 3DCRT series with disease free survival rates ranging between about 40 and $88 \%[4,7]$.

Table 3: Volumetric characteristics of loco-regionally failed (LRF) vs loco-regionally controlled (LRC) patients without vs with late term reactions grade $3 / 4$.

\begin{tabular}{cccc}
\hline & LRF & LRC, G 0-2 & LRC, G 3-4 \\
\hline n & 21 & 77 & $14^{*}$ \\
GTV PT (cc) & 63 & 32 & 31.4 \\
GTV LN (cc) & 8.5 & 15 & 13 \\
PTVI (cc) & 174 & 154 & 176 \\
\% PTVI >110\% & 0.8 & 0.8 & 1.3 \\
\% PTVI < $<5 \%$ & 13.5 & 8.3 & 8.0 \\
\hline
\end{tabular}

Gross tumor volume (GTV) in LRF patients was significantly larger than in controlled LRC individuals ( $P<0.0 \mathrm{I})$. Isodose comparison showed PTVI in controlled patients tendentially better covered, with less volumes getting doses < $95 \%$, compared with failed patients.

* : the 2 patients with xerostomia grade 3 and the 3 patients with ulcers related to tumor persistence were excluded from this analysis. 


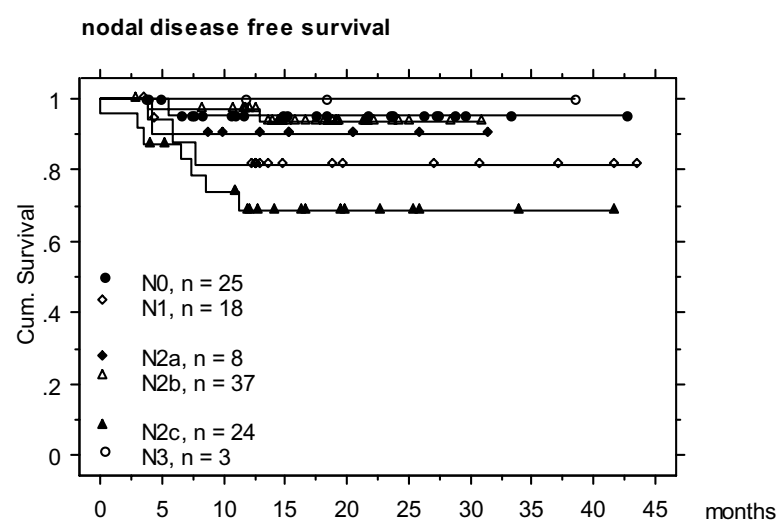

Figure 4

Actuarial 2 year nodal disease free survival according to $\mathrm{N}$ stages (N0 patients remain nodally controlled)

Operated patients in our cohort showed half as large tumors and half the local recurrence rate as primarily irradiated patients. The significant correlation between tumor size and tumor control is shown by several investigators $[8,9]$.

Dawson et al reported on 12/58 failed patients (21\%), of whom $10 / 12$ relapsed in-field, two marginally [1]. Of 17/ $126(13 \%)$ failures in Chao's et al's series [5], 9 were inside the CTV1, one was marginal, one outside the CTV1 but inside CTV2.

Considering own and published results on locoregional failure analyses $[1,5,10,11]$, one can conclude that the volumetric concept used so far in HNC IMRT is appropriate, and the loco-regional control can hardly be improved by volumetric optimisation.

\section{Acute tolerance}

Grade 3 mucositis, dermatitis, and dysphagia rates were $15 \%, 5 \%$, and $20 \%$, respectively, comparing with $50 \%$ to more than $80 \%$ acute mucositis [12-15], and 33\% up to $50-70 \%$ dysphagia $[7,15,16]$ in 3DCRT.

De Arruda et al reported $38 \%$ grade 3 mucositis in 50 SIBIMRT patients, and $6 \%$ grade 3 skin reactions; $62 \%$ developed grade 3 acute reactions [17]. Chao et al [4] found 37 $\%$ grade $3 / 4$ skin toxicity, $40 \%$ grade $3 / 4$ mucositis in 74 oropharyngeal cancer patients necessitating a gastrostomy tube during chemo-IMRT in $23 \%$.

Mucosal and dermal acute reactions occurred only localized and healed up faster in our IMRT patients than used in 3DCRT patients. Only few patients presented with an acute grade 3 mucositis in the boost area. This phenomenon is not entirely understood and may be related to

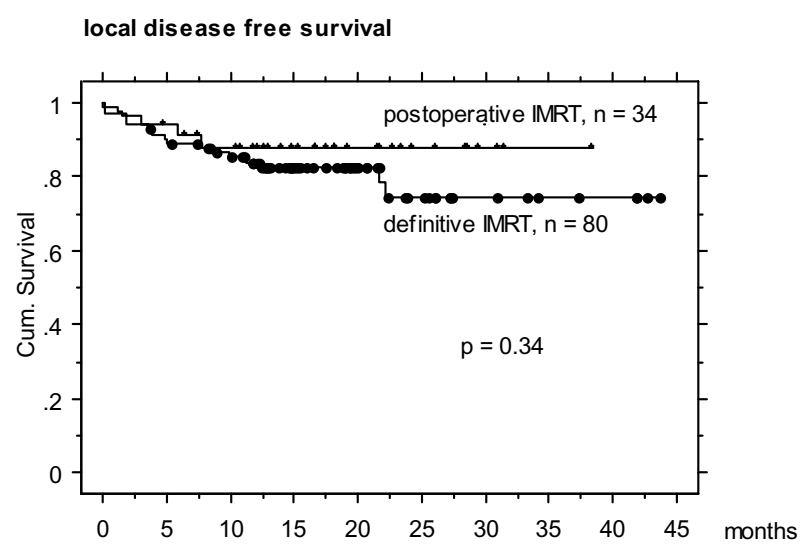

Figure 5

Actuarial 2 year local disease free survival in definitively vs postoperatively irradiated patients (non-significant difference).

improved tissue tolerance when only moderate doses are delivered to adjacent tissue areas.

\section{Late tolerance}

12 subacute grade 3/4 mucosal ulcers in the PTV1 were observed, which were characterized by self-limitation and spontaneous healing. 8/19 patients with late reactions were exposed to $>110 \%$ of prescribed total doses, in only 4 of them hot spots matched with the area of the actinic lesion, indicating the hot spots not to be the main reason for these lesions.

Xerostomia grade 3 at 1 year was scored in 2 (3\%) patients at risk; 3 patients at risk developed dysphagia grade $3 / 4$. In a group of 50 patients, De Arruda et al observed 8 cases $(16 \%)$ of pharyngeal grade 3 reactions in the MSKCC IMRT series; three patients developed cervical esophageal stricture requiring dilatations [17]. In a 3DCRT study by Huguenin et al [7], higher incidences of $12 \%$ and $22 \%$ were reported for xerostomia and dysphagia, respectively. Dysphagia/aspiration related structures have been investigated by Eisbruch et al [18]. Pharyngeal constrictors, glottis and supraglottic larynx have been identified as the anatomic correlates whose damage may cause the symptoms. IMRT can moderately spare these structures; if substantially affected by tumor, hot spots and probably also SIB doses > of 2.0 Gy per fraction should be avoided. Consequently, we avoid SIB $2.2 / 2.11$ in patients where the tumor affects major parts of the larynx.

In 75 patients at risk, one grade 3 osteonecrosis, treated without mandible resection, was diagnosed 4 months after IMRT completion. In 3DCRT, the incidence of osteo- 
Table 2: Characteristics on 2 I patients ( $18 \%$ ) with loco-regional failure (LRF) are listed; patients with isolated distant failure (DF) are not included in this list. Mean time to failure (TTF) was 5 - 6 months in recurred patients; in 8 individuals (I/3) tumor persistence was observed.

\begin{tabular}{|c|c|c|c|c|c|c|c|c|c|c|c|}
\hline Number & Diagnosis & TNM & LRF & DF & Outcome & TTF (m) & $\begin{array}{c}\text { GTV } \\
\text { PT (cc) }\end{array}$ & $\begin{array}{c}\text { GTV } \\
\text { LN (cc) }\end{array}$ & $\begin{array}{l}\text { PTVI } \\
\text { (cc) }\end{array}$ & $\%$ PTV $<95$ & \%PTV < 93\% \\
\hline I & OC & T4N2c & LRR & & $A D$ & 4 & 15 & 3 & 127 & 9 & 5 \\
\hline 2 & OC & T4N2c & LRR & & DOD & 10 & 75 & 27 & 253 & 6 & 3 \\
\hline 3 & OC & TIN2b & LR & distant & DOD & 3 & na & 6.5 & 74 & 5 & 2 \\
\hline 4 & OC & T3N2c & LR & & DOD & 15 & 23 & 1 & 144 & 14 & 9 \\
\hline 5 & OC & $\mathrm{T} 2 \mathrm{NI}$ & LR & & $A D$ & 4 & 45 & 2 & 124 & 5 & 2 \\
\hline 6 & OC & Recurrence & LRR & & $A D$ & 0 & 71 & 6 & 117 & 25 & 17 \\
\hline 7 & OC & T2NO & Persistence & & $A D$ & 0 & 13 & 0 & 64 & 0 & 0 \\
\hline 8 & OC & $\mathrm{T} 2 \mathrm{~N} 2 \mathrm{c}$ & Persistence & & $A D$ & 0 & 16 & 2.4 & 82 & 50 & 7 \\
\hline 9 & OC & $\mathrm{T} 4 \mathrm{NI}$ & Persistence & & DOD & 0 & 206 & 5 & 270 & 4 & I \\
\hline 10 & oro & $\mathrm{T} 4 \mathrm{~N} 2 \mathrm{~b}$ & LR & distant & $A D$ & 13 & 100 & 2 & 255 & 8 & 4 \\
\hline II & oro & $\mathrm{T} 4 \mathrm{~N} 2 \mathrm{c}$ & NR & distant & DOD & 3 & 34 & 15 & 179 & 8 & 4 \\
\hline 12 & oro & T4N0 & Persistence & & DOD & 0 & 57 & 0 & 188 & 5 & 2 \\
\hline 13 & oro & $\mathrm{T} 3 \mathrm{~N} 2 \mathrm{~b}$ & Persistence & distant & $A D$ & 0 & 97 & 5 & 393 & 14 & 5 \\
\hline 14 & oro & T3N2a & Persistence & & $A D$ & 0 & 31 & 4.3 & 198 & 35 & 25 \\
\hline 15 & oro & $\mathrm{T} 4 \mathrm{~N} 2 \mathrm{~b}$ & LRR & & $A D$ & 8 & 41 & 5 & 178 & 15 & 10 \\
\hline 16 & Sinus & T4No & Persistence & & DOD & 10 & 75 & 0 & 75 & 8 & 5 \\
\hline 17 & Sinus & Recurrence & Persistence & distant & $A D$ & 0 & 56 & 20 & 89 & 27 & 11 \\
\hline 18 & Sinus & $\mathrm{T} 4 \mathrm{~N} 2 \mathrm{~b}$ & LRR & & DOD & 15 & $|4|$ & 17 & 176 & 11 & 5 \\
\hline 19 & Glottic & Recurrence & $N R$ & distant & DOD & 13 & 9 & 118 & 8 & 3 & 3 \\
\hline 20 & Supragl & $\mathrm{T} 4 \mathrm{~N} 2 \mathrm{c}$ & LRR & distant & $A D$ & 6 & 79 & 18 & 353 & 7 & 2 \\
\hline 21 & Hypoph & $\mathrm{T} 3 \mathrm{~N} 2 \mathrm{c}$ & NR & & ANED * & 9 & 22 & 30 & 210 & 15 & 7 \\
\hline Mean & & & & & & 5.4 & 63.0 & 8.5 & 174.6 & 13.3 & 6.1 \\
\hline Range & & & & & & $0-21$ & $9-206$ & $0-99$ & $64-353$ & $0-50$ & $0-25$ \\
\hline
\end{tabular}

LRF loco-regional failure; DF distant failure; LC local recurrence; LRR loco-regional recurrence; NR nodal recurrence; TTF time to failure; GTVPT primary gross tumor volume, GTV LN lymph node gross tumor volume; PTVI planning target volume I (boost).

radionecrosis is higher by approximately $4-6 \%$ after 2 years [19], although FU of the presented IMRT cohort is still short for definitive result.

\section{SIB-IMRT}

The advantage of SIB-IMRT consists in a better target conformity [20-24], less dose to critical structures, moderate treatment acceleration with reduced total treatment time, and the option of dose escalation in the gross tumor volume.

There is limited experience in normal tissue tolerance following SIB-IMRT in HNC.

Many different SIB schedules (references [2,17,22-29], two RTOG protocols (H-0022 and 0225)) have been published; to this date there is no universally agreed standard of dosage.

We found SIB 2.11 and SIB ${ }^{2.2}$ equally well tolerated and safe with respect to acute and late normal tissue tolerance compared to 3DCRT, except of the described grade 4 reactions when 2.2 Gy per session delivered to larger laryngeal areas. The weakness of this comparison lies in its retrospective approach.
The unexpected observation of very few ( $15 \%$ ) cases with grade 3 acute mucositis despite full SIB dose delivered to the mucosa, and observed better tissue healing, are interesting and clinically relevant findings that may indicate a higher tolerance, when surrounding tissue volumes are exposed to lower doses. This phenomenon has been described decades ago, based on the clinical observation of the so called 'grid therapy' [30-34], a technique used to deliver high single fraction doses of radiation by converting a large treatment field into many smaller fields. The use of this technique goes back to the beginning of the last century when orthovoltage radiation was mainly used for external beam radiation therapy. Small areas of skin within an irradiated field, shielded from direct radiation, are reported to serve as centers for re-growth of normal skin tissue, and allowed up to six times the conventional open doses without an increase in skin reactions or complications to underlying structures.

Moreover, grade 3/4 late effects could not be related to hot spots in the majority of our cases, indicating additional factors determining normal tissue tolerance in IMRT.

With respect to future proceeding, mild dose escalation limited to the GTV in patients with intermediate tumor 
Table 4: Characteristics on patients with grade $3 / 4$ late term effects ( 19 events in 18 patients). In all cases with grade $3 / 4$ ulcers not healing during a 6 months period ( $n=3$, grey bars), ulcer persistence was found basing on tumor persistence (No 3,13, 16; data from these patient as well as of the 2 individuals with grade 3 xerostomia were excluded from this volumetric analysis (EA) of the 14 patients with grade $3 / 4$ lesions).

\begin{tabular}{|c|c|c|c|c|c|c|c|c|c|c|c|c|c|c|c|}
\hline \multirow[b]{2}{*}{ No. } & \multirow[b]{2}{*}{$\mathrm{Dg}$} & \multirow[b]{2}{*}{ TNM } & \multirow[b]{2}{*}{ Sequence } & \multirow[b]{2}{*}{ Grade 3/4 } & \multirow[b]{2}{*}{ t post RT (m) } & \multirow[b]{2}{*}{ Duration (m) } & \multirow[b]{2}{*}{ Treatment } & \multicolumn{8}{|c|}{ Outcome } \\
\hline & & & & & & & & NTR & Tumor & PTD & $d / f S I B$ & $D \max G 3 / 4$ & $\begin{array}{l}\text { GTV PT } \\
(\mathrm{cc})\end{array}$ & PTVI (cc) & $\begin{array}{c}\mathrm{Cc}>110 \% \\
\mathrm{D}\end{array}$ \\
\hline 1 & Cent oro & T3N2c & Prim & Ulcer & 4 & 7 & - & Healed & ANED & $66 / 54$ & 2.2 & 75.7 & 56 & 213 & 0 \\
\hline 2 & Supragl & $\mathrm{T} 2 \mathrm{~N} 2 \mathrm{~b}$ & Prim & Ulcer & 6 & 1 & - & Healed & ANED & $69.6 / 54$ & 2.11 & 75.9 & 20.8 & 162.5 & 0 \\
\hline 3 & Oral cav & T2No & Postop & Ulcer & 3 & 4 & 0 & Healed & ANED & $66 / 54$ & 2 & 80.7 & 14 & 81.7 & 1.6 \\
\hline 4 & Нуро & T4NI & Prim & Ulcer & 3 & 3 & $\mathrm{HBO}$ & Healed & ANED & $66 / 54$ & 2.2 & 75.8 & 74 & 299 & 0 \\
\hline 5 & & " & $"$ & Larynx fibrosis & 10 & $\begin{array}{l}\text { Persistent } \\
\text { (30) }\end{array}$ & Tracheostoma & Tracheostoma & ANED & " & 2.2 & 75.8 & $"$ & " & 0 \\
\hline 6 & Нуро & $\mathrm{T} 2 \mathrm{~N} 2 \mathrm{~b}$ & Prim & Ulcer & 4 & 5 & - & Healed & ANED & $69.6 / 54$ & 2.11 & 74.8 & 27 & 145 & 0 \\
\hline 7 & Cent oro & $\mathrm{T} 3 \mathrm{~N} 2 \mathrm{~b}$ & Prim & Ulcer & 6 & 1 & - & Healed & ANED & $66 / 54$ & 2.2 & 77.3 & 30 & 201 & 2 \\
\hline 8 & Нуро & $\mathrm{T} 2 \mathrm{~N} 2 \mathrm{~b}$ & Prim & Ulcer & 6 & 2 & - & Healed & ANED & $69.6 / 54$ & 2.11 & 76.8 & 34.5 & 220 & 2.2 \\
\hline 9 & Cent oro & T3No & Prim & Ulcer & 4 & 3 & $\mathrm{HBO}$ & Healed & ANED & $66 / 54$ & 2.2 & 77.3 & 29 & 77.7 & 7.7 \\
\hline 10 & Lat oro & T3N2b & Postop & Ulcer & 2 & 3 & - & Healed & ANED & $65.4 / 54$ & 2.11 & 72.8 & 7.8 & 212 & 0 \\
\hline 11 & Cent oro & $\mathrm{T} 3 \mathrm{~N} 2 \mathrm{~b}$ & Prim & Bone & 4 & 6 & Surgery & Healed & ANED & $66 / 54$ & 2.2 & 76.5 & 37.5 & 208 & 2 \\
\hline 12 & Нуро & T3No & Prim & Dysphagia & 2 & ? (8) & Dilatation & Persistent & ANED & $69.6 / 54$ & 2.11 & 75.7 & 32 & 149.5 & 0 \\
\hline 13 & Нуро & T3N2c & Prim & Dysphagia & 5 & $\begin{array}{l}\text { Persistent } \\
\text { (14) }\end{array}$ & Dilatation & Persistent & ANED & $68.2 / 54$ & 2.2 & 79.2 & 21.5 & 210 & 2.1 \\
\hline 14 & Cent oro & T3N2b & Prim & Dysphagia & 5 & $?(9$, lost $)$ & - & ? & ANED & $69.6 / 54$ & 2.11 & 76.7 & 24 & 113 & 0 \\
\hline 15 & Oral cav & $\mathrm{T} 2 \mathrm{~N} 2 \mathrm{c}$ & Prim & Ulcer & 3 & Persistent & - & Persistent & $\begin{array}{c}\text { TU } \\
\text { Persistent }\end{array}$ & $69.6 / 54$ & 2.11 & EA & EA & EA & EA \\
\hline 16 & Lat oro & T2NI & Prim & Ulcer & 2 & Persistent & - & Persistent & $\begin{array}{c}\text { TU } \\
\text { Persistent }\end{array}$ & $69.6 / 54$ & 2.11 & EA & EA & EA & EA \\
\hline 17 & Cent oro & T3N2b & Prim & $\begin{array}{l}\text { Bleeding } \\
\text { ulcer }\end{array}$ & 0 & Persistent & Surgery & Persistent & $\begin{array}{c}\text { TU } \\
\text { Persistent }\end{array}$ & $69.6 / 54$ & 2.11 & EA & EA & EA & EA \\
\hline 18 & Нуро & $\mathrm{T} 4 \mathrm{~N} 2 \mathrm{a}$ & Prim & Xerostomia & 0 & $\begin{array}{l}\text { Persistent } \\
\text { (14) }\end{array}$ & - & Persistent & ANED & $69.6 / 54$ & 2.11 & EA & EA & EA & EA \\
\hline 19 & Cent oro & TIN2b & postop & Xerostomia & 0 & $\begin{array}{l}\text { Persistent } \\
\text { (12) }\end{array}$ & - & Persistent & ANED & $64 / 54$ & 2 & EA & EA & EA & EA \\
\hline Mean & & & & & 3.6 & 3.2 & & & & & & 76.5 & 31.4 & 176.3 & 1.3 \\
\hline Range & & & & & $0-10$ & $1-7$ & & & & & $2.0-2.20$ & $72.8-80.7$ & $2.5-37.5$ & $78-299$ & $0-7.7$ \\
\hline
\end{tabular}

t postRT time (in months) from IMRT completion to appearance of late term reaction NTR normal tissue reaction

PTD prescribed total dose 
Table 5: Disease outcome following IMRT in selected published series including the own study

\begin{tabular}{|c|c|c|c|c|c|c|c|c|}
\hline Authors & HNC cohorts & $\mathrm{N}$ patients & LC (\%) & NC (\%) & LRC & DC (\%) & OAS (\%) & time point \\
\hline $\begin{array}{c}\text { Eisbruch et al } \\
\text { [II] }\end{array}$ & oro/hypo/OC & 133 & & & $94 / 77 / 60$ & & & $3 y$ \\
\hline $\begin{array}{c}\text { Dawson et al } \\
{[\mathrm{I}]}\end{array}$ & $\begin{array}{l}\text { HNC w/o } \\
\text { NPC }\end{array}$ & 58 & & & 79 & & & $2 y$ \\
\hline Own study & $\begin{array}{l}\text { HNC w/o } \\
\text { NPC }\end{array}$ & 115 & 77 & 87 & & 78 & 86 & $2 y$ \\
\hline $\begin{array}{c}\text { Eisbruch et al } \\
\text { [II] }\end{array}$ & $\begin{array}{l}\text { dIMRT/ } \\
\text { pIMRT }\end{array}$ & $60 / 73$ & & & $81 / 84$ & & & $3 y$ \\
\hline Chao et al [4] & $\begin{array}{l}\text { dIMRT/ } \\
\text { PIMRT }\end{array}$ & $31 / 43$ & & & $78 / 95$ & $84 / 94$ & 87 & $3 y$ \\
\hline Chao et al [5] & $\begin{array}{l}\text { dIMRT/ } \\
\text { PIMRT }\end{array}$ & $52 / 74$ & & & $79 / 90$ & & & $2 y$ \\
\hline own study & $\begin{array}{l}\text { dIMRT/ } \\
\text { PIMRT }\end{array}$ & $80 / 34$ & $81 / 91$ & $86 / 97$ & & $92 / 88$ & $75 / 79$ & $2 y$ \\
\hline $\begin{array}{c}\text { Eisbruch et al } \\
\text { [II] }\end{array}$ & oro & 80 & & & 94 & & & $3 y$ \\
\hline $\begin{array}{l}\text { Garden et al } \\
\text { [in 6] }\end{array}$ & oro & 80 (TI-2N0) & & & 94 & & & $2 y$ \\
\hline De Arruda 17 & oro & 50 & 98 & 88 & & 84 & 98 & $2 y$ \\
\hline $\begin{array}{l}\text { Huang et al } \\
\text { [in 6] }\end{array}$ & oro & 41 & 94 & & 89 & 91 & 89 & $2 y$ \\
\hline Own study & oro & 56 & 88 & 93 & & 93 & 87 & $2 y$ \\
\hline
\end{tabular}

LC local control; NC nodal control; LRC loco-regional control; DC distant control, OAS overall survival; oro oropharyngeal tumor; OC oral cavity tumor; NPC nasopharyngeal cancer; d/PIMRT defintive/postoperative IMRT.

volumes and related intermediate disease outcome, respectively (manuscript submitted: disease outcome related to GTV), is in evaluation as a first consequence of these data.

\section{Conclusion}

IMRT in HNC, using the planning target volume and dose concept as described, is a highly effective technique with respect to tumor response and tolerance. SIB-IMRT is safe and similarly well tolerated using either 2.11 or 2.2 Gy per fraction to total doses of 66-70 Gy, although is not recommended for large tumors involving laryngeal structures.

There is clinical evidence for increased normal tissue tolerance following IMRT.

\section{Methods}

\section{SIB schedules}

SIB was performed in 109/115 patients; in the remaining six cases a single dose-volume was painted.

\section{Biomathematical consideration}

In order to employ a slightly accelerated SIB schedule, 30 $\times 2.2$ Gy per fraction, 5× per week, to 66 Gy in the high dose area (PTV1), was chosen. This corresponds with the BED of $35 \times 2$ Gyper session, 5x / week, to 70 Gy in terms of early and late tolerance, assuming an alpha value of 0.35 , and an alpha/beta ratio of 10 and 3, respectively (BED for late effects 116.66, BED for early effects 70.1
Gy). Similarly, 2.11 Gy per fraction in 33 sessions to 69.6 Gy (PTV1) equals with $35 \times 2$ Gy to 70 Gy.

SIB-IMRT technique was performed using the following schedules (5 fractions/week each):

2.2 Gy (PTV1) / 1.8 Gy (PTV2) to 66 Gy / 54 Gy, 5 fractions/week $\left(\mathrm{n}=33, \mathrm{SIB}^{2.2}\right)$

2.11 Gy (PTV1)/1.64 Gy (PTV2) to 69.6 Gy / 54 Gy, 5 fractions/week $\left(\mathrm{n}=44, \mathrm{SIB}^{2.11}\right)$

2.11 (PTV1) / 1.8 Gy (PTV2) to 63.3 / 54 Gy, 5 fractions/ week $\left(n=3, \operatorname{SIB}^{2.11}\right)$

2.0 Gy (PTV1)/ 1.5-1.8 Gy (PTV2) to 60 - 70 / 52-56 Gy, $5-6$ fractions/week $\left(\mathrm{n}=34, \mathrm{SIB}^{2.0}\right)$

In one patient with large necrotic nodes, a higher SIB dose of 2.35 Gy per fraction to 75.2 Gy was delivered.

During the first 20 months, SIB-IMRT was performed with $\mathrm{SIB}^{2.2}$ according to the RTOG study protocol H-0022.

Intermediate doses were individually defined to regions considered at high risk for microscopic disease (PTV3, doses ranging from $56-60 \mathrm{~Gy}$ ).

In 7 / 33 patients subacute mucosal ulcers were observed. As a consequence the decision was made to change the 


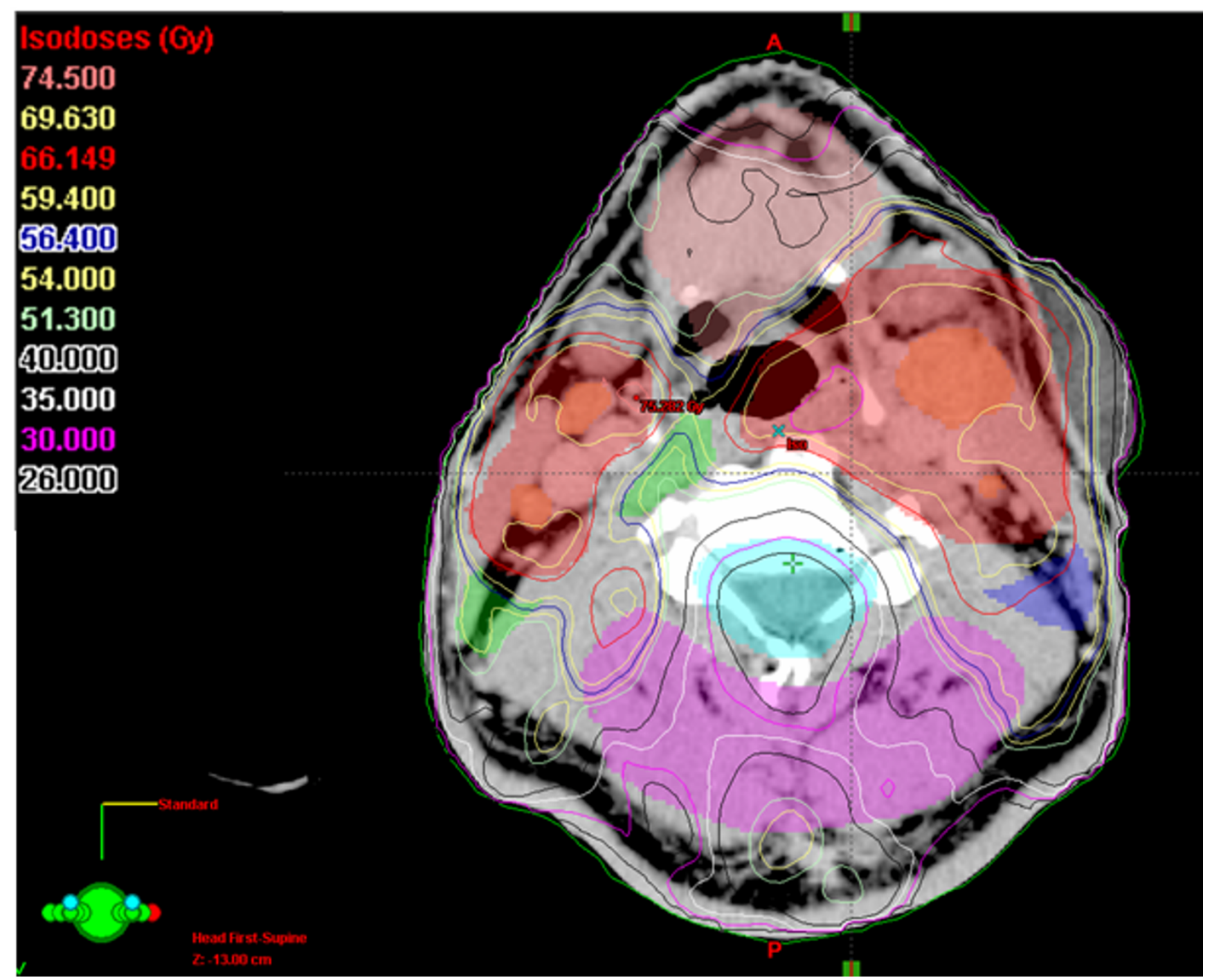

Figure 6

An example of an IMRT isodose plan using simultaneously integrated boost. Depicted is an axial slice, $64 \mathrm{~mm}$ above the isocenter of the plan. Contoured are PTVI (69.6 Gy), PTV2 (60 Gy) and PTV3 (54 Gy), gross tumor volumes of the primary and macroscopic nodal disease, and normal structures (spinal cord, brain, parotid glands, anterior soft tissues, dorsal soft tissues). Note the well-spared spinal cord and parotid glands despite of bilateral nodal disease covered with high doses (nodal and primary gross tumor volumes included into the PTVI).

$\mathrm{SIB}^{2.2}$ schedule to a slightly less accelerated schedule with 2.11 / 1.64 Gy per fraction to 63.3 - 69.6 / 54 Gy in 30 33 fractions $(n=47)$.

In all patients with tumor extension close to, or invading the central nervous system (CNS), and in most patients treated in a postoperative setting $(n=22 / 34)$, SIB 2.0 was prescribed. Doses to CNS structures never exceeded 2.0 Gy per fraction and 70 Gy total dose, respectively.

\section{Planning Computerized Tomography (Planning CT)}

Planning CT (Somatom Plus 4, Siemens) was acquired with $2-3 \mathrm{~mm}$ slice thickness and no interslice gap throughout the whole sequentially acquired region of interest. Patients were immobilized in a commercially available thermoplastic mask with fixed head and shoulder. An integrated individually customized bite block.

In patients with postoperative irradiation gross tumor volumes were drawn slice by slice in the planning CT, based on diagnostic preoperative MRIs and PET-CTs, which were available for all patients. In the majority of the definitively 


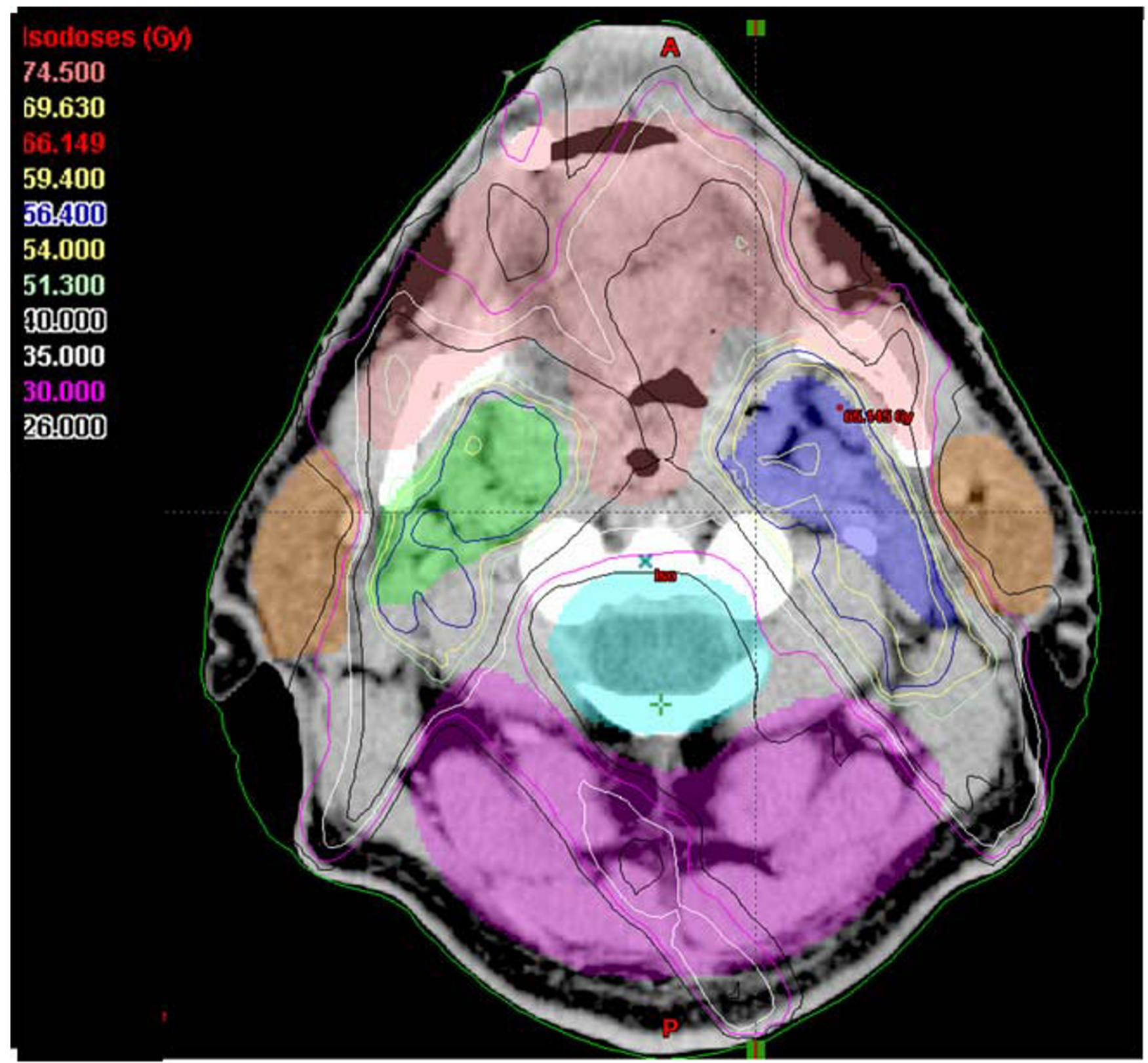

\section{Figure 7}

An example of an IMRT isodose plan using simultaneously integrated boost. A more distal axial slice $12 \mathrm{~mm}$ above the isocenter

irradiated patients, fused 'PET-Planning CTs' were performed.

\section{Planning systems}

Contouring and plan optimisation was performed on a Varian Treatment Planning System (Eclipse ${ }^{\circledast}$, Version 7.3.10, Varian Medical Systems, Hansen Way, Palo Alto CA, 94304-1129)

\section{Delineation of planning target volumes (PTVs)}

Definitions

Gross Tumor Volume (GTV) with a margin of 10-15 mm was included in the SIB volume (PTV1, 60 - 73 Gy)

Elective lymph node regions (PTV2, doses between 48 56 Gy):

In hypopharyngeal, central oropharyngeal and lateral oropharyngeal tumors extending to midline structures, 


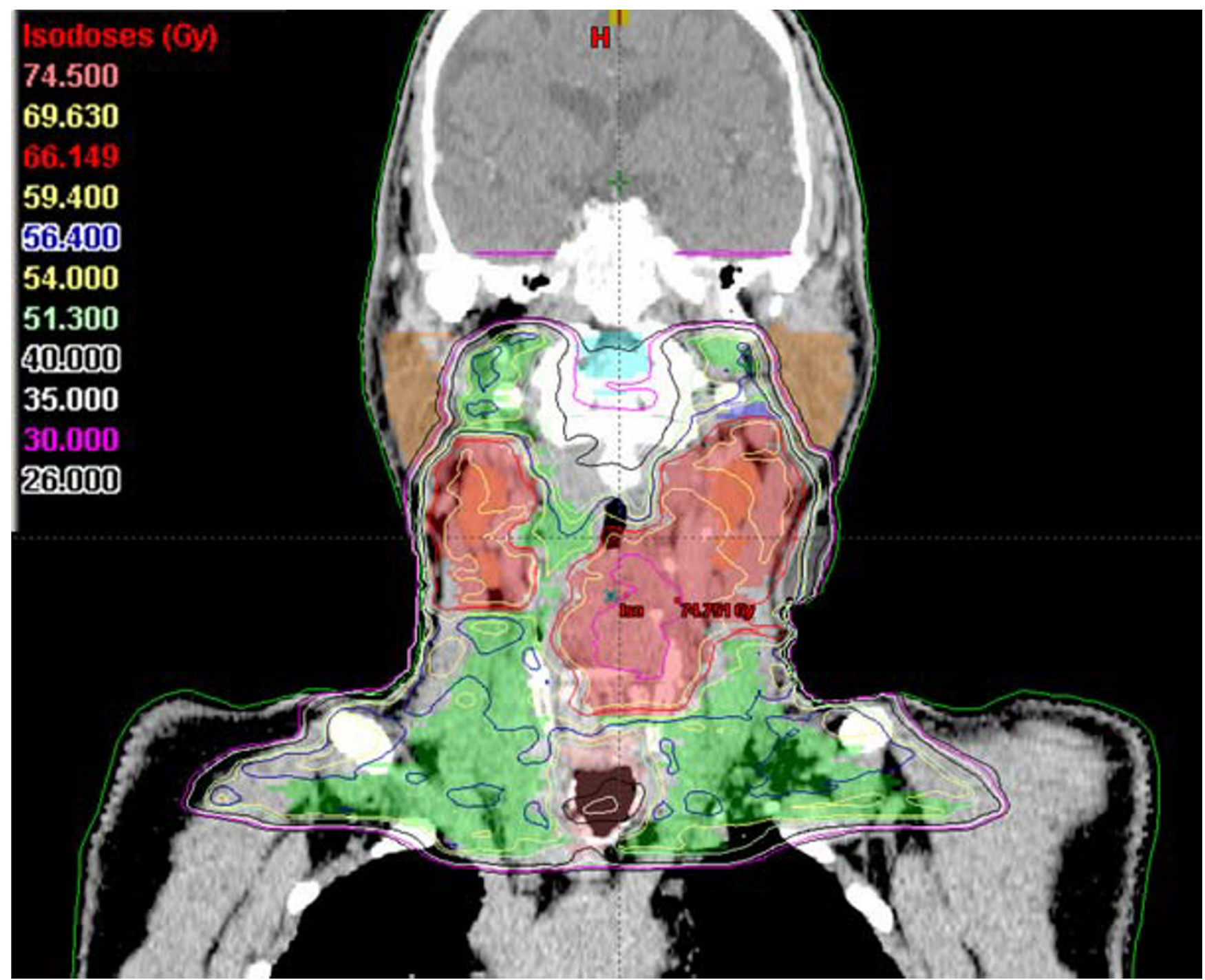

\section{Figure 8}

An example of an IMRT isodose plan using simultaneously integrated boost. A sagital view of a T2N2c staged hypopharyngeal cancer patient.

bilateral lymph node regions level 2 - 5 and retropharyngeal nodes were included.

In lateral oropharynx tumors with bilateral nodal disease, bilateral nodes level $2-5$ were irradiated. In cases with minimal contralateral nodal disease, level $2-5$ excluding the uppermost part of contralateral level 2 was included. In nodally negative lateral T1-2 oropharynx tumors without infiltration of the tongue and without palatinal infiltration crossing the midline, the elective node irradiation was limited to the ipsilateral side. In T3/4 N0 or ispilateral N1/2 situations, ipsilateral level $2-5$ and contralateral level 2 - 4 without the uppermost part were included, respectively.
Submandibular nodes have been electively included only in oral cavity tumors, or in tumors extending to the oral cavity.

Dose constraints for normal tissues / organs at risk (OARs) outside PTVs (see also Figures 6, 7, 8, 9)

Dose planning aimed at target doses of 60 - 70 Gy. Normal tissue doses were defined as follows:

Spinal cord/brain stem: maximum dose (Dmax) < 45 Gy, mean dose (Dmean) < 35 Gy (spinal cord was contoured with an at least $5-10 \mathrm{~mm}$ margin, $>10 \mathrm{~mm}$ at the ventral aspect) 


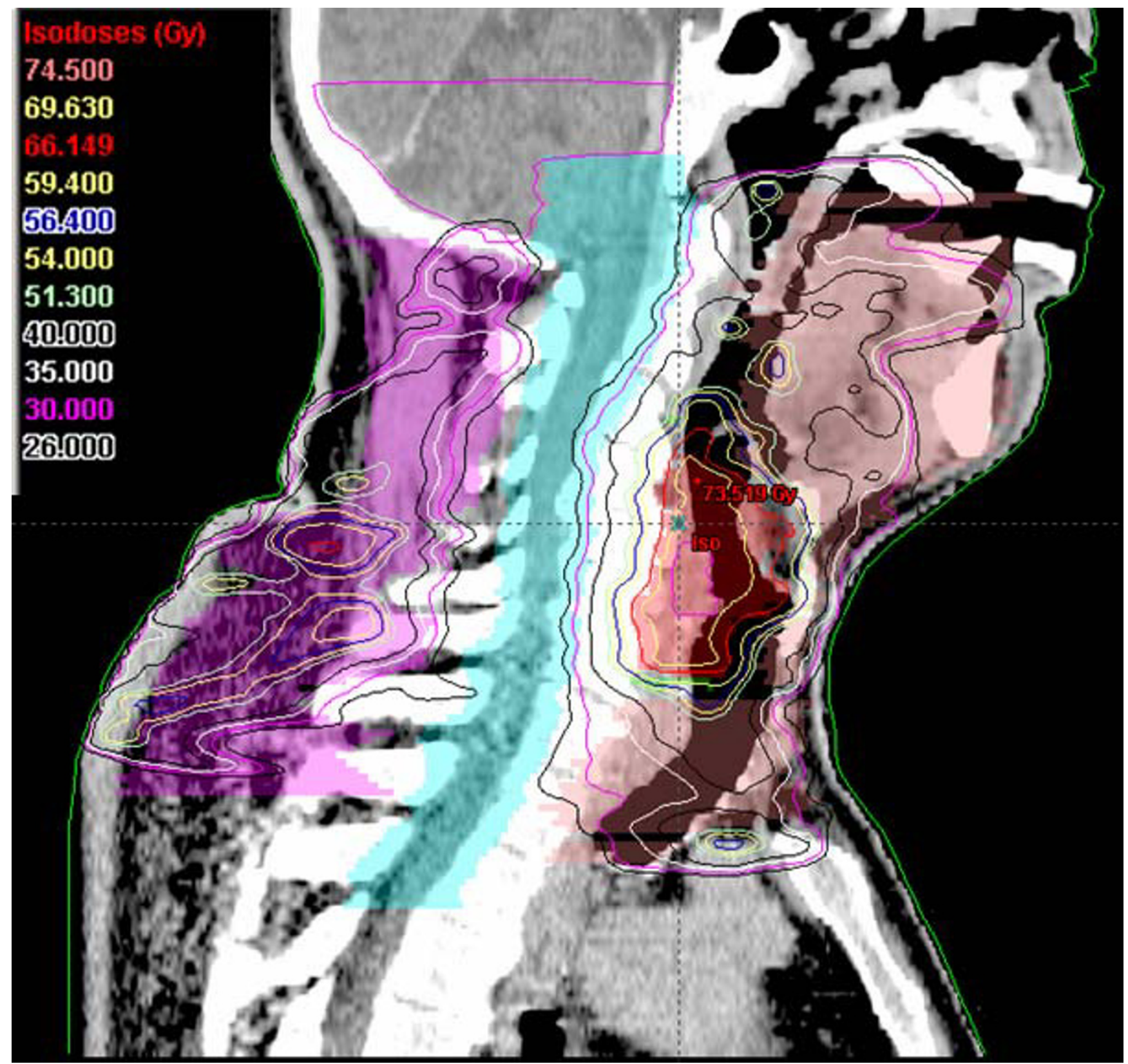

\section{Figure 9}

An example of an IMRT isodose plan using simultaneously integrated boost. A coronar view of a T2N2c staged hypopharyngeal cancer patient.

Parotid (entire or partial) gland volume, spared to the degree possible without compromising target coverage: Dmean < 26 Gy (outlined was the partial volume provided to be spared, no overlapping with PTVs; contouring of the entire glands for analytic purposes)

Optic nerve outside PTV: Dmax < 50 Gy (optic nerve, retina and chiasm were contoured with a safety margin of 2 $-4 \mathrm{~mm})$
Chiasm: Dmax < 50 Gy

Retina outside PTV: Dmax < 45 Gy

Lacrimal glands: Dmax $<30$ Gy

Brain: depending CNS vicinity to the tumor; Dmax $\leq 100$ $\%$ of prescribed total dose of maximal $70 \mathrm{~Gy}$, doses per fraction of 1.8-2.0 Gy 
Temporomandibular joint (TMJ): Dmax < 50 Gy

Oral cavity outside the PTV (contouring included the mandible and maxillary bone and the oral vestibulum): Dmean < 35 Gy

Nuchal tissue: Dmean $<45$ Gy

\section{Radiation}

Irradiation was delivered by $6 \mathrm{MV}$ photon beams on a Varian linear accelerator with sliding window technique. The technical solution of choice was a 5 field arrangements ('class solution') for most patients ( $\mathrm{n}=100) ; 6$ fields were applied in 7, 7 fields in 8 patients.

Patient alignment was checked before radiation by portal imaging. Deviations of $>2 \mathrm{~mm}$ in nasopharyngeal cancers and paranasal sinus tumors, of $>3 \mathrm{~mm}$ in all other tumors, respectively, were corrected before treatment. Three-dimensional position deviations from the digitally reconstructed radiographs (DRRs) were compared and calculated automatically (lateral and axial deviation, rotation).

In the first 30 patients treated with IMRT at our institution, the accepted deviation was only $2 \mathrm{~mm}$, independent of the diagnosis. The position in all patients used to be checked on a daily base for the entire treatment time and was prospectively analysed.

Deviations of $>2 \mathrm{~mm}$ occurred in 108 out of 241 evaluated treatment sessions in patients $(1: 2.2$ incorrect-to-correct position-ratio); $2 / 3$ of all deviations that required a pre-treatment correction were observed in patients with large fields (when lymphatic pathways included in the treatment volume).

Based on those data we went over to a) an accepted $3 \mathrm{~mm}$ deviation for all patients except of those with sinonasal and nasopharyngeal tumors, and b) to the following portal vision check rhythm: daily checks only in the first three treatment days, followed by a once to twice a week portal vision check in all patients in whom positioning is initially found in the tolerated range. Every correction was followed by another daily check period of three days.

The dose homogeneity within the PTV was aimed to be in close accordance with the RTOG guidelines:

The dose was normalized to the mean dose in PTV1 which corresponds, in the majority of cases, approximately to the $95 \%$ dose level in that volume.

- The prescription dose is the isodose which encompasses at least $95 \%$ of the PTV
- no more than $20 \%$ of any PTV will receive $>110 \%$ of it's prescribed dose

- no more than $1 \%$ of PTV1 will receive $<93 \%$ of its prescribed dose

- no more than $1 \%$ or $1 \mathrm{cc}$ of the tissue outside the PTV will receive $>110 \%$ of the dose prescribed to the primary PTV

\section{Clinical quality assurance (QA)}

- Follow up

During the course of irradiation, all patients were clinically assessed at regular weekly intervals, and 2 weeks and 2 months after completion of treatment.

Approximately 6 weeks after completion, all patients were also seen regularly in our joint clinics at the Department of Head and Neck Surgery or Maxillofacial Surgery. Further follow up visits were scheduled every $2-3$ months in the first 2 years, $3-4$ monthly in the third year. When clinical and/or endoscopic examination showed no evidence of disease no radiological investigations were performed; suspect findings were specified with CT-PET, suspect lymph nodes by needle aspiration and/or biopsy, respectively.

\section{- QA with respect to posttreatment events}

Isodose plans of all patients who experienced locoregional failure or grade $3 / 4$ late term effects were reviewed at the radiation planning work station, in order to check local dose distributions at the regions of interest.

- QA with respect to quality of life (QoL)

Toxicity was assessed based on SOMA LENT and RTOG/ EORTC Radiation Morbidity Score. Both classifications have been considered; for simplification, grade 3 or 4 late reactions were termed 'grade $3 / 4$ ' reactions.

Patients' QoL was prospectively assessed prior, during the course of radiation, and 2 weeks, then 2, 6, 12, 18, and 24 months following IMRT (EORTC/RTOG-QLQ; results in preparation).

StatView ${ }^{\oplus}$ program Version 4.5 was used for calculation of Kaplan Meier actuarial survival curves. Mann-Whitney-U test was used for comparison of volumes. P values $<0.05$ were considered statistically significant.

\section{Declaration of competing interests}

The author(s) declare that they have no competing interests. 


\section{Authors' contributions}

GS and CG designed the study and analysed the data, GS carried out the data collection and drafted the manuscript. PH participated in collecting data and created the data base. BD reviewed and corrected the manuscript, BD and GK participated in drafting the 'methods'. UML reviewed and corrected the manuscript. All authors read and approved the final manuscript. The authors are the responsible physicians and physicists for the IMRT program.

\section{References}

I. Dawson LA, Anzai Y, Marsh L, Martel MK, Paulino A, Ship JA, Eisbruch $A$ : Patterns of local-regional recurrence following parotidsparing conformal and segmental intensity-modulated radiotherapy for head and neck cancer. Int J Radiat Oncol Biol Phys 2000, 46: I II7-II 26.

2. Lee N, Xia P, Quivey JM, Sultanem K, Poon I, Akazawa C, Akazawa P, Weinberg $V$, Fu KK: Intensity-modulated radiotherapy in the treatment of nasopharyngeal carcinoma: an update of the UCSF experience. Int J Radiat Oncol Biol Phys 2002, 53:I2-22.

3. Lee N, Xia P, Fischbein NJ, Akazawa P, Akazawa C, Quivey JM: Intensity-modulated radiation therapy for head-and-neck cancer: the UCSF experience focusing on target volume delineation. Int I Radiat Oncol Biol Phys 2003, 57:49-60.

4. Chao KS, Ozyigit G, Blanco Al, Thorstad WL, Deasy JO, Haughey BH, Spector G], Sessions DG: Intensity-modulated radiation therapy for oropharyngeal carcinoma: impact of tumor volume. Int J Radiat Oncol Biol Phys 2004, 59:43-50.

5. Chao KS, Ozyigit G, Tran BN, Cengiz M, Dempsey JF, Low DA: Patterns of failure in patients receiving definitive and postoperative IMRT for head-and-neck cancer. Int J Radiat Oncol Biol Phys 2003, 55:3|2-32|

6. Puri DR, Chou $W$, Lee $N$ : Intensity-modulated radiation therapy in head and neck cancers: dosimetric advantages and update of clinical results. Am / Clin Oncol 2005, 28:4I5-423.

7. Huguenin P, Beer KT, Allal A, Rufibach K, Friedli C, Davis JB, Pestalozzi B, Schmid S, Thoni A, Ozsahin M, Bernier J, Topfer M, Kann R, Meier UR, Thum P, Bieri S, Notter M, Lombriser N, Glanzmann C: Concomitant cisplatin significantly improves locoregional control in advanced head and neck cancers treated with hyperfractionated radiotherapy. J Clin Oncol 2004, 22:4665-4673.

8. Mendenhall WM, Morris CG, Amdur RJ, Hinerman RW, Mancuso AA: Parameters that predict local control after definitive radiotherapy for squamous cell carcinoma of the head and neck. Head Neck 2003, 25:535-542.

9. Kurek R, Kalogera-Fountzila A, Muskalla K, Dafni U, Schnabel T, Kober B, Roddiger S, Martin T, Fountzilas G, Zamboglou N: Usefulness of tumor volumetry as a prognostic factor of survival in head and neck cancer. Strahlenther Onkol 2003, I 79:292-297.

10. Eisbruch A, Ship JA, Dawson LA, Kim HM, Bradford CR, Terrell JE, Chepeha DB, Teknos TN, Hogikyan ND, Anzai Y, Marsh LH, Ten Haken RK, Wolf GT: Salivary gland sparing and improved target irradiation by conformal and intensity modulated irradiation of head and neck cancer. World J Surg 2003, 27:832-837.

I I. Eisbruch A, Marsh LH, Dawson LA, Bradford CR, Teknos TN, Chepeha DB, Worden FP, Urba S, Lin A, Schipper MJ, Wolf GT: Recurrences near base of skull after IMRT for head-and-neck cancer: implications for target delineation in high neck and for parotid gland sparing. Int J Radiat Oncol Biol Phys 2004, 59:28-42.

12. Brizel DM, Albers ME, Fisher SR, Scher RL, Richtsmeier WJ, Hars V, George SL, Huang AT, Prosnitz LR: Hyperfractionated irradiation with or without concurrent chemotherapy for locally advanced head and neck cancer. N Engl J Med 1998, 338: $1798-1804$.

13. Adelstein DJ, Saxton JP, Lavertu P, Tuason L, Wood BG, Wanamaker JR, Eliachar I, Strome M, Van Kirk MA: A phase III randomized trial comparing concurrent chemotherapy and radiotherapy with radiotherapy alone in resectable stage III and IV squa- mous cell head and neck cancer: preliminary results. Head Neck 1997, 19:567-575.

14. Buntzel J, Schuth J, Kuttner K, Glatzel M: Radiochemotherapy with amifostine cytoprotection for head and neck cancer. Support Care Cancer 1998, 6:155-160.

15. Bieri S, Bentzen SM, Huguenin P, Allal AS, Cozzi L, Landmann C, Monney $M$, Bernier J: Early morbidity after radiotherapy with or without chemotherapy in advanced head and neck cancer. Experience from four nonrandomized studies. Strahlenther Onkol 2003, I 79:390-395.

16. Nguyen NP, Moltz CC, Frank C, Vos P, Smith HJ, Karlsson U, Dutta S, Midyett FA, Barloon J, Sallah S: Dysphagia following chemoradiation for locally advanced head and neck cancer. Ann Oncol 2004, I 5:383-388.

17. de Arruda FF, Puri DR, Zhung J, Narayana A, Wolden S, Hunt M, Stambuk H, Pfister D, Kraus D, Shaha A, Shah J, Lee NY: Intensitymodulated radiation therapy for the treatment of oropharyngeal carcinoma: The memorial sloan-kettering cancer center experience. Int J Radiat Oncol Biol Phys 2005.

18. Eisbruch A, Schwartz M, Rasch C, Vineberg K, Damen E, Van As CJ, Marsh R, Pameijer FA, Balm AJ: Dysphagia and aspiration after chemoradiotherapy for head-and-neck cancer: which anatomic structures are affected and can they be spared by IMRT? Int J Radiat Oncol Biol Phys 2004, 60: |425-I439.

19. Studer G, Gratz KW, Glanzmann C: Osteoradionecrosis of the mandibula in patients treated with different fractionations. Strahlenther Onkol 2004, 180:233-240.

20. Fogliata A, Bolsi A, Cozzi L, Bernier J: Comparative dosimetric evaluation of the simultaneous integrated boost with photon intensity modulation in head and neck cancer patients. Radiother Oncol 2003, 69:267-275.

2I. Dogan N, King S, Emami B, Mohideen N, Mirkovic N, Leybovich LB, Sethi A: Assessment of different IMRT boost delivery methods on target coverage and normal-tissue sparing. Int J Radiat Oncol Biol Phys 2003, 57:|480-I49I.

22. Wu Q, Mohan R, Morris M, Lauve A, Schmidt-Ullrich R: Simultaneous integrated boost intensity-modulated radiotherapy for locally advanced head-and-neck squamous cell carcinomas. I: dosimetric results. Int J Radiat Oncol Biol Phys 2003, 56:573-585.

23. Mohan R, Wu Q, Manning M, Schmidt-Ullrich R: Radiobiological considerations in the design of fractionation strategies for intensity-modulated radiation therapy of head and neck cancers. Int J Radiat Oncol Biol Phys 2000, 46:619-630.

24. Lauve A, Morris M, Schmidt-Ullrich R, Wu Q, Mohan R, Abayomi O, Buck D, Holdford D, Dawson K, Dinardo L, Reiter E: Simultaneous integrated boost intensity-modulated radiotherapy for locally advanced head-and-neck squamous cell carcinomas: Il--clinical results. Int J Radiat Oncol Biol Phys 2004, 60:374-387.

25. Ozyigit G, Chao KS: Clinical experience of head-and-neck cancer IMRT with serial tomotherapy. Med Dosim 2002, 27:91-98.

26. Butler EB, Teh BS, Grant WH, Uhl BM, Kuppersmith RB, Chiu JK, Donovan DT, Woo SY: Smart (simultaneous modulated accelerated radiation therapy) boost: a new accelerated fractionation schedule for the treatment of head and neck cancer with intensity modulated radiotherapy. Int J Radiat Oncol Biol Phys 1999, 45:21-32.

27. Chao KS, Deasy JO, Markman J, Haynie J, Perez CA, Purdy JA, Low DA: A prospective study of salivary function sparing in patients with head-and-neck cancers receiving intensitymodulated or three-dimensional radiation therapy: initial results. Int I Radiat Oncol Biol Phys 200I, 49:907-916.

28. Vineberg KA, Eisbruch A, Coselmon MM, McShan DL, Kessler ML, Fraass BA: Is uniform target dose possible in IMRT plans in the head and neck? Int J Radiat Oncol Biol Phys 2002, 52: I I 59-I I 72.

29. van Asselen B, Dehnad H, Raaijmakers CP, Roesink JM, Lagendijk JJ, Terhaard $\mathrm{CH}$ : The dose to the parotid glands with IMRT for oropharyngeal tumors: the effect of reduction of positioning margins. Radiother Oncol 2002, 64:197-204.

30. Marks $\mathrm{H}$ : Clinical experience with irradiation through a grid. Radiology 1952, 58:338-342.

31. Reiff JE, Huq MS, Mohiuddin M, Suntharalingam N: Dosimetric properties of megavoltage grid therapy. Int J Radiat Oncol Biol Phys 1995, 33:937-942.

32. Trapp JV, Warrington AP, Partridge M, Philps A, Glees J, Tait D, Ahmed R, Leach MO, Webb S: Measurement of the three- 
dimensional distribution of radiation dose in grid therapy. Phys Med Biol 2004, 49:N3 I7-23.

33. Miller RC, Wilson KG, Feola JM, Urano M, Yaes RJ, McLaughlin P, Maruyama Y: Megavoltage grid total body irradiation of C3Hf/ SED mice. Strahlenther Onkol 1992, 168:423-426.

34. Lin KH, Huang CY, Lin JP, Chu TC: Surface dose with grids in electron beam radiation therapy. Appl Radiat Isot 2002, 56:477-484.

35. Gregoire V, Coche E, Cosnard G, Hamoir M, Reychler H: Selection and delineation of lymph node target volumes in head and neck conformal radiotherapy. Proposal for standardizing terminology and procedure based on the surgical experience. Radiother Oncol 2000, 56:135-150.

36. Lu TX, Mai WY, Teh BS, Zhao C, Han F, Huang Y, Deng XW, Lu LX, Huang SM, Zeng ZF, Lin CG, Lu HH, Chiu JK, Carpenter LS, Grant WH, Woo SY, Cui NJ, Butler EB: Initial experience using intensity-modulated radiotherapy for recurrent nasopharyngeal carcinoma. Int / Radiat Oncol Biol Phys 2004, 58:682-687.

37. Munter MW, Debus J, Hof H, Nill S, Haring P, Bortfeld T, Wannenmacher $M$ : Inverse treatment planning and stereotactic intensity-modulated radiation therapy (IMRT) of the tumor and lymph node levels for nasopharyngeal carcinomas. Description of treatment technique, plan comparison, and case study. Strahlenther Onkol 2002, I 78:5 17-523.

38. Som PM, Curtin HD, Mancuso AA: An imaging-based classification for the cervical nodes designed as an adjunct to recent clinically based nodal classifications. Arch Otolaryngol Head Neck Surg 1999, 125:388-396.

39. Som PM, Curtin HD, Mancuso AA: Imaging-based nodal classification for evaluation of neck metastatic adenopathy. AJR Am J Roentgenol 2000, 174:837-844.

Publish with Bio Med Central and every scientist can read your work free of charge

"BioMed Central will be the most significant development for disseminating the results of biomedical research in our lifetime. "

Sir Paul Nurse, Cancer Research UK

Your research papers will be:

- available free of charge to the entire biomedical community

- peer reviewed and published immediately upon acceptance

- cited in PubMed and archived on PubMed Central

- yours - you keep the copyright

Submit your manuscript here:

http://www.biomedcentral.com/info/publishing_adv.asp
BiolMedcentral 